\title{
Synthesis of the spiroketal core of integramycin
}

Evgeny. V. Prusov

\author{
Letter \\ Address: \\ Department of Medicinal Chemistry, Helmholtz Centre for Infection \\ Research, Inhoffenstr. 7, 38124 Braunschweig, Germany \\ Email: \\ Evgeny. V. Prusov - evgeny.prusov@helmholtz-hzi.de \\ Keywords: \\ anti-infectives; hydrozirconation; natural products; spiroketals; total \\ synthesis
}

\begin{abstract}
Beilstein J. Org. Chem. 2013, 9, 2446-2450.
doi:10.3762/bjoc.9.282
\end{abstract}

Received: 14 August 2013

Accepted: 23 October 2013

Published: 12 November 2013

This article is part of the Thematic Series "Natural products in synthesis and biosynthesis".

Guest Editor: J. S. Dickschat

(C) 2013 Prusov; licensee Beilstein-Institut.

License and terms: see end of document.

\begin{abstract}
A concise synthetic strategy towards the spiroketal core of the HIV-integrase inhibitor integramycin (1) was developed. The required ketone precursor was efficiently constructed from two simple and easily accessible subunits by means of a hydrozirconation/copper catalyzed acylation reaction. The effects of different protecting groups on the spiroketalization step were also investigated.
\end{abstract}

\section{Findings}

Integramycin is a polyketide natural product isolated from Actinoplanes sp. by the Singh group at Merck [1] (Figure 1). The compound was found to inhibit HIV-1 integrase coupled strand transfer reactions with $\mathrm{IC}_{50}$ values of 3 and $4 \mu \mathrm{M}$, respectively. Structurally, the molecule architecture of integramycin features four distinct elements: a 3,5-dihydroxysubstituted aromatic ring, a spiroketal core, a highly functionalized octalin moiety and a 5-hydroxylated 3 -acyltetramic acid. Studies on the syntheses of the spiroketal core $[2,3]$ and the octalin fragment [4] of integramycin were recently reported by Roush and Floreancig, however, a total synthesis of this rather complex natural product has yet to be accomplished. Intrigued by its biological properties and capitalizing on our previous experience [5] in the total synthesis of natural products with tetramic acid fragments we embarked on the development of a concise and modular approach towards integramycin and related natural products.

According to the retrosynthetic analysis, which is outlined in Figure 2, the target molecule may be assembled from an appropriate spiroketal advanced intermediate 4 . This spiroketal compound is logically traced back to ketone $\mathbf{5}$, which can be further divided in the vicinity of the C22 carbonyl group into two readily accessible building blocks 6 and 7. For the construction of the octalin fragment we planned to use two sequential olefination reactions followed by an intramolecular Diels-Alder cycloaddition. The installation of the tetramic acid moiety would proceed via Lassey-Dickmann condensation with subsequent introduction of the 5-hydroxy group by oxidation of the corresponding vinylogous enolate. Herein a straightforward 

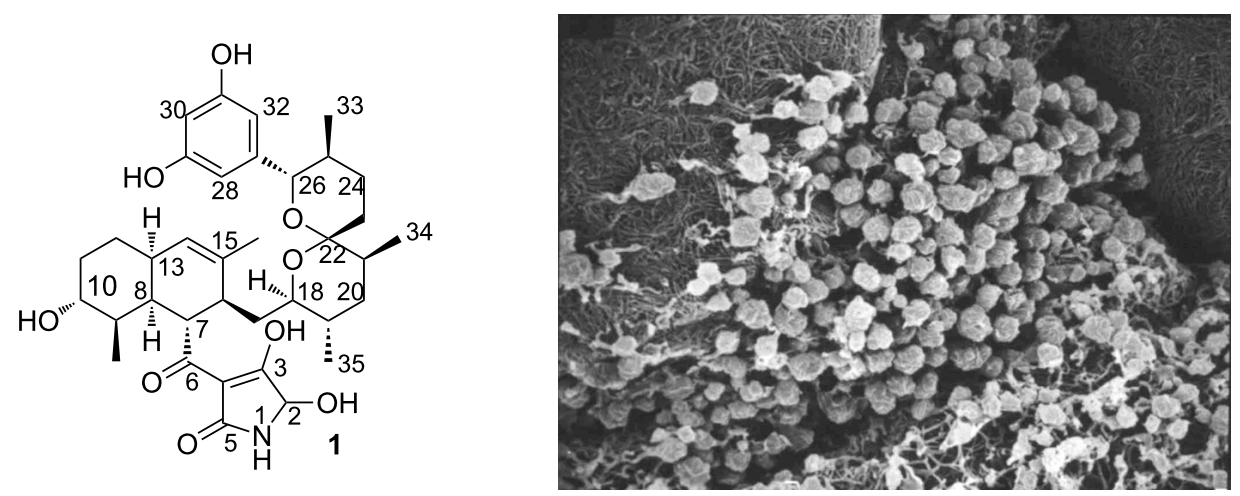

Figure 1: Structure of integramycin (1) and its producing organism, Actinoplanes sp. (Photo: J. Wink, HZI, Microbial drugs).

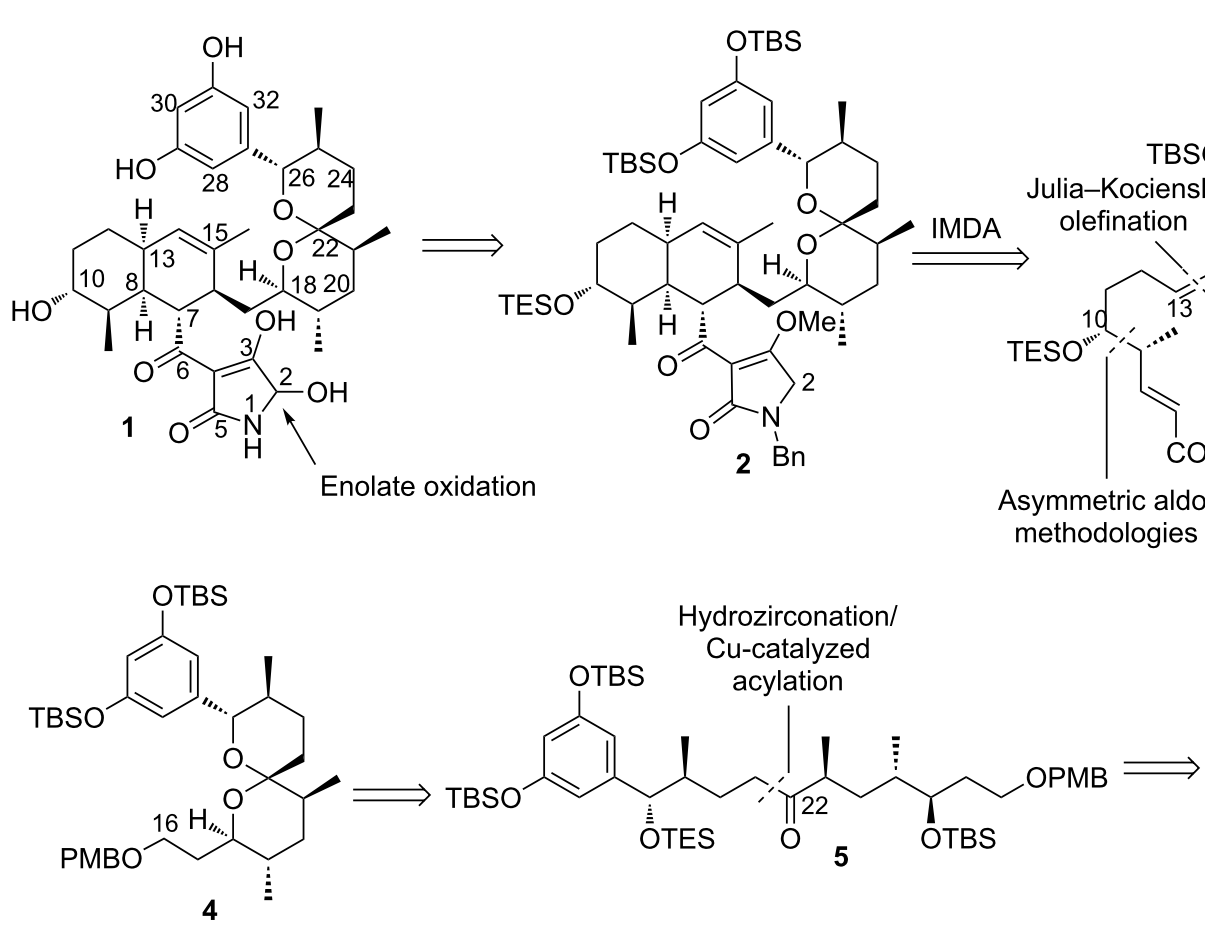

Figure 2: Retrosynthetic analysis of integramycin.

synthesis of the C16-C35 spiroketal core of integramycin based on a hydrozirconation/acylation reaction sequence is reported.

The synthesis of the aryl-substituted part of the spiroketal fragment was started from 3,5-dihydroxybenzoate 8 which was converted into aldehyde 9 via protection and partial reduction [6] (Scheme 1). Subsequent Leighton crotylation [7] using commercially available $(R, R)$-E-Crotyl-Mix was employed to introduce the two stereocenters at $\mathrm{C} 25 / \mathrm{C} 26$ with anti-relationship in excellent yield and enatioselectivity. The enantiomeric excess of the crotylation product was estimated by esterifica- tion with $(R)$ - $\alpha$-methoxyphenylacetic acid with subsequent NMR analysis and found to be close to $90 \%$. The resulting alcohol was protected as TBS and TES ethers to investigate the cleavage regime of different protecting groups during the acid catalyzed ketalization step.

The second part of the spiroketal core was constructed from the PMB-protected 3-hydroxypropanal via Horner-WadsworthEmmons olefination, reduction to the allylic alcohol and Sharples epoxidation [8] (Scheme 2). Subsequent Cu-catalyzed epoxide-opening using methylmagnesium bromide [9] produced 


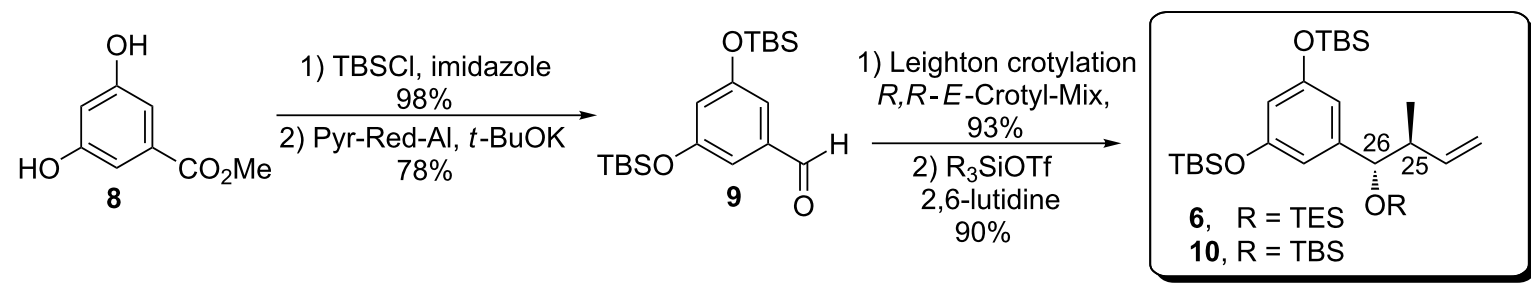

Scheme 1: Synthesis of the aromatic subunit.
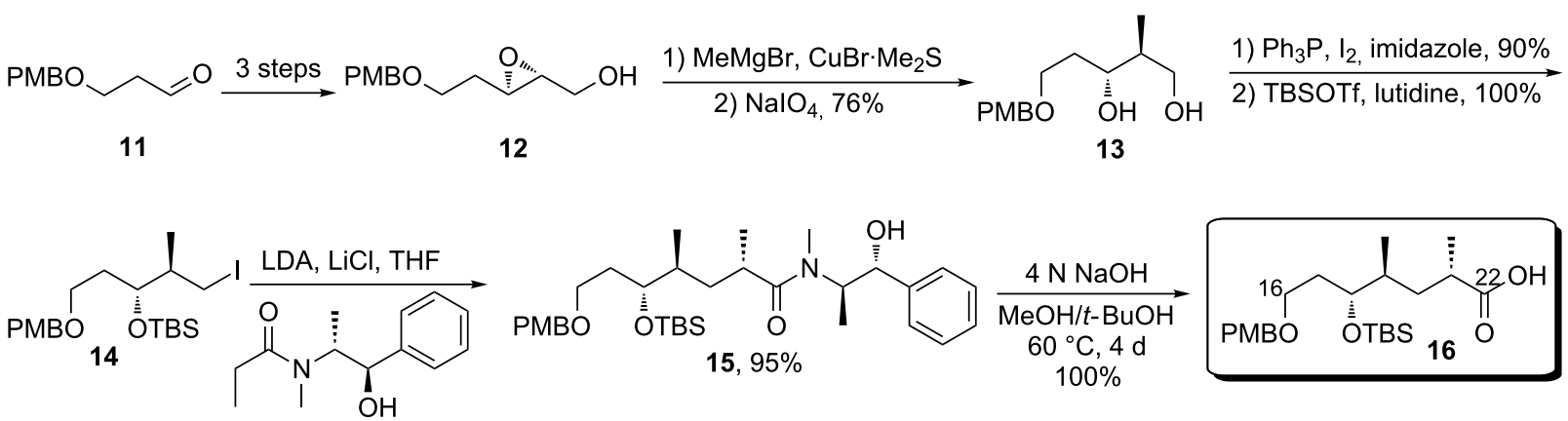

Scheme 2: Sharpless epoxidation/Myers alkylation approach to the C16-C22 carboxylic acid fragment.

an inseparable mixture of 1,2- and 1,3-diol products, which upon treatment with sodium periodate furnished pure 13. The primary hydroxy group was selectively converted to alkyl iodide by using $\mathrm{Ph}_{3} \mathrm{P} / \mathrm{I}_{2} /$ imidazole conditions [10]. Then the protected iodide $\mathbf{1 4}$ was subjected to Myers alkylation [11] reaction with an excess of enolate to install the last required stereocenter. Hydrolytic cleavage of the pseudoephedrine auxiliary by prolonged exposure to sodium hydroxide at elevated temperature afforded the carboxylic acid $\mathbf{1 6}$.

With both fragments in hand, the key coupling was attempted. Initially, the conditions recently reported by Vasse [12] were investigated (Scheme 3). In the event, treatment of the carboxylic acid 16 with Ghosez reagent [13] provided the corresponding acid chloride 7 , which was allowed to react with the hydrozirconation products of alkenes $\mathbf{6}$ and $\mathbf{1 0}$ in dichloromethane in the presence of a stoichiometric amount of $\mathrm{CuBr} \cdot \mathrm{Me}_{2} \mathrm{~S}$. The reaction was rather capricious and produced only modest amounts of the target compound. However, application of the original Wipf protocol [14] resulted in a much more favourable outcome and, upon some further optimization of the catalyst load, provided the desired ketone in $65 \%$ yield for the TBS protected alkene. The yield for the TES-protected alkene was somewhat lower, probably due to a partial cleavage of the protecting group during the acylation or hydrozirconation step.
Finally, several conditions were studied for the spiroacetalization step. Exposure of the all-TBS protected ketone 17 to moderately strong acids, e.g. the HF-pyridine complex in THF or CSA in $\mathrm{THF} / \mathrm{H}_{2} \mathrm{O}$ mixture, resulted in the predominant cleavage of the TBS group at $\mathrm{C} 18$, whereas the benzylic TBS ether remained mostly untouched. Application of more acidic conditions ( $3 \mathrm{~N} \mathrm{HCl}$ in THF) led to a messy reaction. However, treatment of the same ketone with an excess of TBAF buffered with acetic acid caused removal of all protecting groups with concomitant spiroketalization and upon reinstallation of the phenolic protecting groups the desired compound 4 was obtained in 35\% yield. The stereochemistry of the spiroketal was confirmed by observation of the strong NOE-correlation for H-18 and H-22 protons in the NOESY spectrum of 4 (see Supporting Information File 2). In the case of the ketone with the TES-protected benzylic alcohol, exposure to $2 \mathrm{~N} \mathrm{HCl}$ in THF resulted in formation of numerous products, including the spiroketal 4, thus demanding further optimization of this reaction.

In summary, an efficient route to the C16-C35 spiroketal fragment of integramycin was developed. The key step of the synthesis is a Cu-catalysed coupling of an acid chloride with an alkyl zirconium species. The stereocenters were introduced using Leighton crotylation, Sharpless epoxidation and Myers alkylation. Although the presented route achieves approxi- 


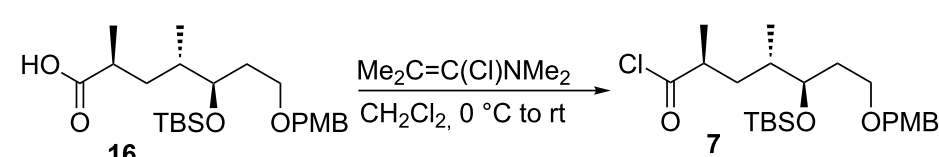

16

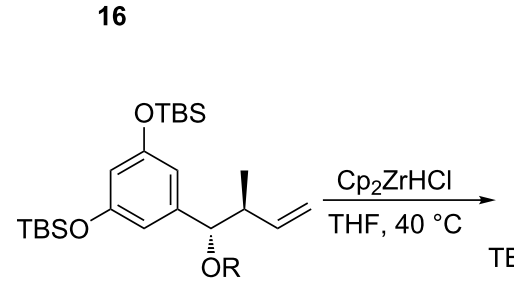

6, $R=T E S$ $10, R=T B S$

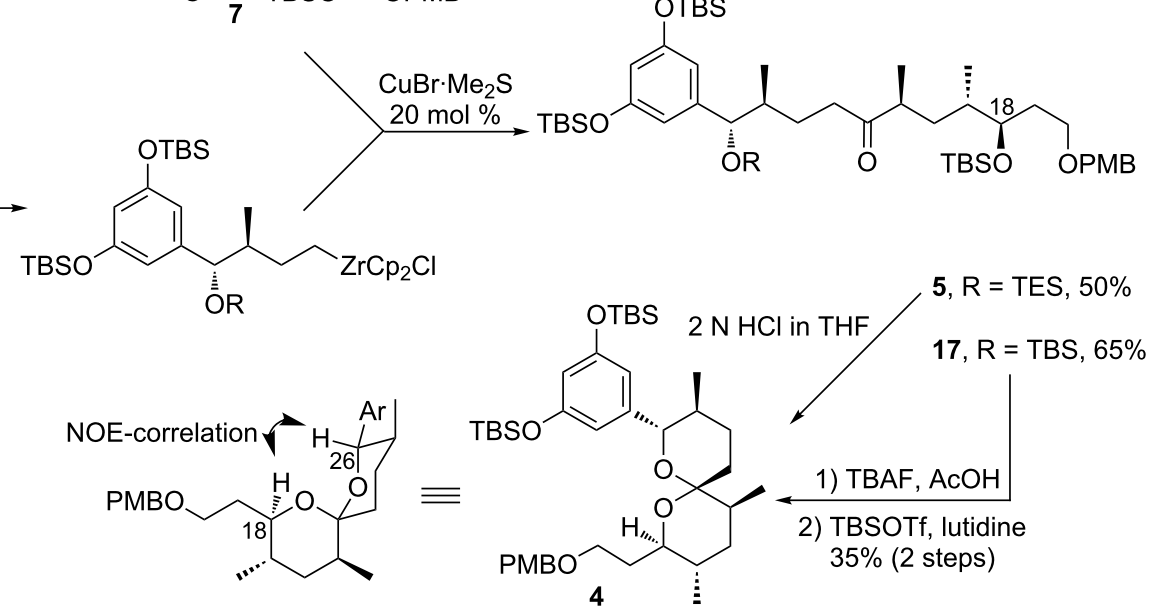

OTBS

Scheme 3: Coupling of the fragments and spiroketalization.

mately the same overall yield of target compound as that of Floreancig [2] (11.2 vs 11.5\%, respectively), it features utilization of easily scalable transformation and upon further optimization of the spiroketalization step would be advantageous for the preparation of intermediate 4. Efforts towards the completion of the total synthesis of integramycin are currently underway in our laboratory and will be reported in due course.

\section{Supporting Information}

\section{Supporting Information File 1}

Experimental procedures.

[http://www.beilstein-journals.org/bjoc/content/ supplementary/1860-5397-9-282-S1.pdf]

\section{Supporting Information File 2}

Copies of NMR spectra.

[http://www.beilstein-journals.org/bjoc/content/ supplementary/1860-5397-9-282-S2.pdf]

\section{References}

1. Singh, S. B.; Zink, D. L.; Heimbach, B.; Genilloud, O.; Teran, A.; Silverman, K. C.; Lingham, R. B.; Felock, P.; Hazuda, D. J. Org. Lett. 2002, 4, 1123-1126. doi:10.1021/ol025539b

2. Wang, L.; Floreancig, P. E. Org. Lett. 2004, 6, 569-572. doi:10.1021/ol036339i

3. Sun, H.; Abbott, J. R.; Roush, W. R. Org. Lett. 2011, 13, 2734-2737. doi:10.1021/ol200834p

4. Dineen, T. A.; Roush, W. R. Org. Lett. 2005, 7, 1355-1358. doi:10.1021/ol050191g
5. Höfle, G.; Gerth, K.; Reichenbach, H.; Kunze, B.; Sasse, F.; Forche, E.; Prusov, E. V. Chem.-Eur. J. 2012, 18, 11362-11370. doi:10.1002/chem.201201879

6. Abe, T.; Haga, T.; Negi, S.; Morita, Y.; Takayanagi, K.; Hamamura, K. Tetrahedron 2001, 57, 2701-2710. doi:10.1016/S0040-4020(01)00143-0

7. Kim, H.; Ho, S.; Leighton, J. L. J. Am. Chem. Soc. 2011, 133, 6517-6520. doi:10.1021/ja200712f

8. Katsuki, T.; Sharpless, K. B. J. Am. Chem. Soc. 1980, 102, 5974-5976. doi:10.1021/ja00538a077

9. Hodgson, D. M.; Arif, T. Org. Lett. 2010, 12, 4204-4207. doi:10.1021/ol101843q

10. Paterson, I.; Britton, R.; Delgado, O.; Gardner, N. M.; Meyer, A.; Naylor, G. J.; Poullennec, K. G. Tetrahedron 2010, 66, 6534-6545. doi:10.1016/j.tet.2010.01.083

11. Myers, A. G.; Yang, B. H.; Chen, H.; McKinstry, L.; Kopecky, D. J.; Gleason, J. L. J. Am. Chem. Soc. 1997, 119, 6496-6511. doi:10.1021/ja970402f

12. Coia, N.; Mokhtari, N.; Vasse, J.-L.; Szymoniak, J. Org. Lett. 2011, 13, 6292-6295. doi:10.1021/ol202796w

13. Devos, A.; Remion, J.; Frisque-Hesbain, A.-M.; Colens, A.; Ghosez, L. J. Chem. Soc., Chem. Commun. 1979, 1180-1181. doi:10.1039/C39790001180

14. Wipf, P.; Xu, W. Synlett 1992, 718-720. doi:10.1055/s-1992-21466 


\section{License and Terms}

This is an Open Access article under the terms of the Creative Commons Attribution License

(http://creativecommons.org/licenses/by/2.0), which permits unrestricted use, distribution, and reproduction in any medium, provided the original work is properly cited.

The license is subject to the Beilstein Journal of Organic Chemistry terms and conditions:

(http://www.beilstein-journals.org/bjoc)

The definitive version of this article is the electronic one which can be found at:

doi:10.3762/bjoc. 9.282 